\title{
HIGIENE CONTRA LA ANEMIA DE LOS MINEROS. LA LUCHA CONTRA LA ANQUILOSTOMIASIS EN ESPAÑA (1897-1936)*
}

\section{Esteban Rodríguez Ocaña y Alfredo Menéndez Navarro}

\author{
Departamento de Historia de la Ciencia. Universidad de Granada
}

\section{RESUMEN}

Este trabajo analiza la participación española en la campaña internacional contra la anquilostomiasis durante el periodo de constitución y hegemonía de la Medicina social. A través del estudio de las principales intervenciones realizadas, incluyendo el acuerdo con la Fundación Rockefeller, se observan sus efectos sobre la popularización de la medicina de laboratorio, la introducción de la preocupación por la salud en la legislación laboral y la génesis de estructuras nuevas para la sanidad rural.

PALABRAS CLAVE: Anquilostomiasis, Campañas sanitarias, Inspección de Sanidad del Campo, Inspección de Sanidad Minera, Fundación Rockefeller, Saneamiento, Análisis de heces.

\begin{abstract}
This study analyses the Spanish participation in the international campaign against ancylostomiasis during the period of the establishing and hegemony of Social Medicine. Through study of the main interventions carried out, including the agreement with the Rockefeller Foundation, its effects are observed on the popularization of laboratory medicine, the introduction of health concerns into employment legislation and the genesis of new rural health structures.
\end{abstract}

KEY WORDS: Ancylostomiasis, Health Campaigns, Rural Health Inspection, Mining Health Inspection, Rockefeller Foundation, Sanitation, Faeces Analysis.

\section{INTRODUCCIÓN: UNA MODÉLICA ENFERMEDAD-DIANA}

La incorporación de las doctrinas y procedimientos del laboratorio físicoquímico al acervo médico conllevó efectos perdurables en todos los ámbitos

* Trabajo realizado dentro del Proyecto BHA2001-2979-C05-01, con financiación del Ministerio de Ciencia y Tecnología. 
de la praxis biomédica. Uno de los más importantes, sin duda, resultó ser el establecimiento de una concepción de las enfermedades desde el punto de vista de una causa material o biológica de procedencia externa a los cuerpos humanos, que resultó del desarrollo de la toxicología, la parasitología y la bacteriología ${ }^{1}$. Esta visión produjo, a lo largo de la segunda mitad del siglo XIX y comienzos del XX, una reordenación de los saberes clínicos en torno a dichas causas universales, en detrimento de la característica multiplicidad ligada a las condiciones particulares de los enfermos con que se habían descrito e identificado similares grupos de signos y síntomas con anterioridad ${ }^{2}$. De esta forma, distintos tipos de anemia, caracterizados como «clorosis egipcia», «anemia tropical», «anemia de Georgia», «anemia de los túneles» o «anemia de los mineros», entre otras, se fundieron en una entidad unitaria denominada anquilostomiasis o uncinariasis, fundada en torno a la existencia de parásitos de alguna de las especies de anquilostoma susceptibles de afectar a los seres humanos, Anchylostoma duodenale (identificado en Italia por Angelo Dubini en 1838, endémica en Europa) o Necator americanus (detectada en Estados Unidos por Charles Stiles en 1902 y localizada endémicamente también en Asia y África) ${ }^{3}$.

A partir de 1880 en Europa, en particular en distritos mineros, y 19001901 en Puerto Rico y Estados Unidos, fundamentalmente en zonas agrícolas, se comenzó a levantar un mapa de prevalencia de la anquilostomiasis que generó una gran preocupación social ${ }^{4}$. La realización de una encuesta a escala

1 López Piñero, J. M. (2002), La medicina en la historia, Madrid, La Esfera de los Libros, 2002, pp. 532-541; Cunningham, A. (1992), The laboratory revolution in medicine, Cambridge, Cambridge University Press; Worboys, M. (2000), Spreading Germs: Disease Theories and Medical Practice in Britain, 1865-1900, Cambridge University Press, y WoRBOYS, M. (1996), «Germs, Malaria and the Invention of Mansonian Tropical Medicine: From 'Diseases in the Tropic' to 'Tropical Diseases'», en D. Arnold (ed.), Warm Climates and Western Medicine, Amsterdam, Rodopi, pp. 181-207.

2 RodríGuez OCAÑA, E. (1995), «Medicina y epidemias. De la racionalización del mito al mito de la racionalización», en Josep L. Barona (ed.), Malaltia i cultura, València, Seminari d'Estudis sobre la Ciència [Trobades], pp. 207-224.

3 Más tardíamente se descubrió en Oceanía que alguna otra especie, que afecta principalmente a perros, puede también causar la enfermedad humana. DocK, G.; BASS, C. C. (1910), Hookworm disease. Etiology, pathology, diagnosis, prognosis, prophylaxis and treatment, St. Louis, C.V. Mosby Company; CHANDLER, A. C. (1929), Hookworm Disease. Its Distribution, Biology, Epidemiology, Pathology. Diagnosis, Treatment and Control, London, Macmillan and Co., Ltd.; LANE, C. (1932), Hookworm Infection, London etc., Oxford University Press.

4 «Introduction», en Bibliography of hookworm disease (1922), New York, Rockefeller Foundation, p. XVII; Dock, BASS (1910), pp. 33-37; BELLONI, L.(1972), «L'anemia del Gottardo», Gesnerus, 29, 33-44. 
internacional en torno a 1910 desveló la gravedad de la afectación de las zonas tropicales, un cinturón de $30^{\circ}$ a cada lado del Ecuador, habitado por unos mil millones de personas. Establecido desde 1880 también el reservorio humano de la infección y su transmisión asociada a las migraciones, la anquilostomiasis se convirtió en bandera y diana de un modelo de intervención sanitaria que por agencia de la Fundación Rockefeller se convirtió en internacional. En el establecimiento del consenso científico en torno a este padecimiento hubo dos momentos cruciales. Entre 1880-1883 se establecieron los elementos fundamentales de la vida del parásito, su transmisión a partir de los huevos depositados en las heces de los afectados (se pensaba que por vía oral, hasta 1903-05 no quedó asumido que la puerta de entrada era básicamente la piel), su diagnóstico mediante examen microscópico de heces y un tratamiento eficaz, con vermífugos como el extracto de éter de helecho macho o el aceite de timol (que, ocasionalmente, producía complicaciones destacables). Todo esto hacía posible descubrirla, evitarla mediante saneamiento de los terrenos y prácticas higiénicas y combatirla en los enfermos. Hacia 1915 comenzó a extenderse un nuevo producto terapéutico, el tetracloruro de carbono, que se había empezado a usar en 1900, y diez años después el tetracloroetileno. Esto hizo que a finales de la tercera década del siglo veinte se pensara que no existía otra enfermedad humana tan perfectamente conocida y controlable ${ }^{5}$. Por tal motivo, se convirtió en una enfermedad social ejemplar a efectos de conseguir visibilidad y legitimidad social para la tarea de la salud pública. De hecho, a partir de sendas reuniones internacionales celebradas en 1903, el Congreso internacional minero y el de Higiene y Demografía de Bruselas, y en 1904, el Congreso socialista en Ámsterdam, se consolidó el impulso social de lucha contra dicha afección, que siguió siendo estimulada en sendas sesiones monográficas en los primeros Congresos internacionales de Enfermedades Profesionales (Roma, 1907, y Bruselas, 1910)

Desde finales del siglo XIX, se sucedieron las campañas de intervención en diversos países: en Bélgica, de ámbito regional a partir de 1899 y con ex-

5 Chandler (1929), p. 13; Luengo, E. (1928), «La anquilostomiasis en las minas españolas. Conferencia en la Escuela de Minas», Revista Minera, Metalúrgica y de Ingeniería, 79 (núm. 3.115), 165-170.

6 Codina Castellví, J. (1912), La anquilostomiasis o anemia de los mineros como enfermedad social, especialmente en España, Madrid, Eduardo Arias, pp. 37-41. José Úbeda publicó un amplio extracto del congreso bruselense, donde se presentaron al menos quince comunicaciones sobre este problema: ÚBEDA CORREAL, J. (1914), El II Congreso internacional de enfermedades profesionales (Bruselas, 1910), Madrid, Suc. Minuesa de los Ríos, pp. 230-250. 
tensión nacional tras el decreto de 7 de agosto de 1900 (la obligación de aplicar tratamiento se estableció el 24 de octubre de 1904); y en Alemania, comenzando por ciertas compañías hulleras de Westfalia en 1892 (extendidas a partir de finales de 1902 y por ley de 13 de julio de 1903). En un contexto distinto, eminentemente campesino, se desarrollaron campañas en Puerto Rico, a partir de 1904, y en el sur de Estados Unidos, gracias a la intervención de la Comisión sanitaria creada en 1909 por la Fundación Rockefeller, la cual, transformada en Junta de sanidad internacional (International Health Board -en adelante, IHB-) a partir de 1915, articuló numerosos estudios y proyectos de lucha en diversos países del mundo ${ }^{7}$. Los éxitos rápidamente alcanzados en las zonas templadas y más industrializadas del mundo contribuyeron a fijar una imagen de la anquilostomiasis como enfermedad de los países tropicales, hasta el punto de estimarse que, después del paludismo, esta sería la afección «causante de la mayor infelicidad e ineficiencia, así como, indirectamente, de un número no despreciable de muertes» ${ }^{8}$. Su característica insidiosidad, falta de episodios de afectación aguda con grave riesgo para la salud, la haría un enemigo aún más peligroso en la consideración de los sanitarios que defendieron la realización de grandes campañas de intervención contra ella, como expresó el informe anual de la IHB en 1917, donde se la hacía responsable del retraso de los pueblos afectados: "This one disease, where the infection is practically universal, may go far towards explaining the retardation of backward peoples $\rangle^{9}$. Es importante advertir que, en nuestra opinión, los problemas inherentes al combate y prevención contra la anquilostomiasis resultaron diferentes según los contextos sociolaborales, de manera que aquí no entramos a considerar la dimensión tropical / colonial de los mismos. Sin embargo, recientemente se ha advertido que la divisoria más importante en los modos de afrontar la enfermedad vendría definida por el objetivo último que presidiera la intervención, «d'éradiquer l'infestation, ou, alternativement, d'atténuer ses effets sur les populations infectées», lo que permitiría establecer paralelismos mayores entre la lucha antianquilostomiásica en Alemania y en la colonia de la Guayana británica que entre la primera y la campaña minera en Francia ${ }^{10}$. Desde nuestro punto de vista, es un artificio

7 Dock, BASS (1910), pp. 33-37; CODINA (1912), pp. 41-59; «Introduction», en Bibliography (1922), pp. XI-XXVI.

8 BoyCOTT, A. E. Milroy lectures on Ankylostoma infection. The Lancet, [18 March, 25 March, 1 April] 1911, citado por LANE (1932), p. 262.

9 Citado en ChANDler (1929), p. 3.

10 LÖWY, I. (2003), «'Intervenir et représenter’: campagnes sanitaires et élaboration des 
enfrentar, como alternativos, ambos objetivos, que se dieron históricamente unidos. Será el contexto concreto de cada caso (tipo de dispositivos concretos diseñados, relaciones sociales entre los agentes expertos y las poblaciones, etc.) el que permita apreciar el carácter de la representación de la enfermedad que resulta operativo en ese particular momento y lugar. La prueba más decisiva en que podemos fundarnos estriba en la diferente historia de la lucha antipalúdica española, entre la metrópoli y las colonias africanas de España, e incluso entre estas mismas ${ }^{11}$.

Este trabajo pretende analizar el lugar de la participación española en estos procesos, tanto en la perspectiva de lo que la experiencia española pudo contribuir al desarrollo internacional cuanto de los efectos de la misma para la salud pública hispana, durante el periodo de constitución y hegemonía de la medicina social. Para ello seguimos la pista de las noticias médicas y sanitarias sobre la presencia y extensión de dicha enfermedad, así como sobre las principales intervenciones realizadas, teniendo en cuenta que la anquilostomiasis fue objeto singular del acuerdo con la IHB de la Fundación Rockefeller, sobre cuyo significado ya hemos reflexionado en trabajos anteriores.

\section{LA APARICIÓN DE LA ANQUILOSTOMIASIS EN ESPAÑA}

España permaneció ajena a la secuencia de observaciones y experiencias que iniciaron la instauración de la alarma sobre esta enfermedad parasitaria. No hay pruebas de que se reconociera su existencia por médicos españoles en el ámbito colonial, cuando por ejemplo en Puerto Rico, a partir de 1899 se detectó por médicos norteamericanos una enorme prevalencia (del $90 \%$ entre los campesinos de la isla, se dijo en una sesión de la Academia de Medicina de Madrid, «con pena para España») ${ }^{12}$. Es más, la tesis de Demetrio Castellana Moreno, leída en Madrid en 1895, sobre la anemia de los países cálidos [...] que se padece en Filipinas, descartó taxativamente dicha etiología a fa-

cartographies de l'ankylostomiase», Hist. Phil. Life Sci., 25, 337-362 [cita de p. 359].

11 Rodríguez Ocaña, E.; Ballester, R.; Perdiguero, E.; Medina, R.; Molero, J. (2003), La acción médico-social contra el paludismo en la España metropolitana y colonial del siglo XX, Madrid, CSIC.

12 Bailey K. Ashford, un teniente médico del Ejército de los Estados Unidos, comenzó a diagnosticar anquilostomiasis en Puerto Rico en 1899, lo que dio lugar a una enérgica campaña a partir de 1904. Sobre los cambios sufridos en la explicación de la anemia tropical y su significado social, véase Trigo, B. (1999), «Anemia and Vampires: Figures to Govern the Colony, Puerto Rico, 1880 to 1904», Comp. Stud. Soc. Hist., 41, 104-123. 
vor de una explicación de tipo climático, en espera de que se descubriera un «fitoparásito (bacteria) especial» ${ }^{13}$.

Sin embargo, en el verano de 1882, Rodríguez Méndez dio cuenta de que los trabajos de Perroncito en Francia, con posterioridad a su intervención en el Gotardo, permitían identificar esta parasitosis como la causa de la anemia minera, a la vez que sugería que se tuviera en cuenta en España ${ }^{14}$.

La falta de identificación de la parasitosis hasta 15 años después hablaría de su tardanza en alcanzar nuestro país, a diferencia de la rápida extensión del contagio por otros europeos, singularmente Hungría o Bélgica, o de lo moderado de su padecimiento, como también ocurrió inicialmente en Inglaterra. Era notoria la ausencia de inmigración obrera extranjera en las cuencas mineras españolas, mientras que algunos de los primeros autores en tratar este problema en suelo hispánico señalaron la posible importación colonial, tras la derrota de 1898; pero esta hipótesis no fue confirmada por los diagnósticos parasitarios. Tampoco hay que descartar el retraso en incorporar las técnicas microscópicas necesarias para su correcto diagnóstico en el ámbito de la medicina minera, desempeñada por los médicos titulares de los pueblos cercanos en muchas ocasiones. En España, los indicios de que disponemos señalan que la familiaridad con los análisis hematológicos más simples sólo se consiguió a partir de la extensión de la lucha antipalúdica, a mediados de la década de 1920, si bien había comenzado su difusión en torno a 1910-12. Esto atestiguaba un médico murciano en 1927: «en los últimos quince años ha variado mucho el desempeño de nuestras funciones de exploración [...] los exámenes de sangre que antes eran la excepción son hoy la regla general $[\ldots]\rangle^{15}$.

En abril de 1897, la revista Industria minera, metalúrgica y mercantil, notificaba los primeros casos en suelo hispano, a través del médico Enrique de Lara, afincado en Linares ${ }^{16}$. El primer fallecido conocido por causa de anquilostomiasis fue el ingeniero Gabriel Molina, muerto el 11 de febrero -en realidad, hubo tres afectados simultáneos, dos ingenieros, uno de ellos de

13 Castellana y Moreno, D. (1895), De la anemia de los países cálidos y ... de la que se padece en las islas Filipinas. Tesis de Doctorado, Madrid, Viuda de M. Minuesa de los Ríos.

14 Rodríguez MÉndez, R. (1882), «Anquilostoma duodenal», La Clínica (Zaragoza), pp. $294 ; 302-303$.

15 Guillamón, A. (1927), «El problema de la anquilostomiasis en la Huerta de Murcia. Memoria de la campaña de divulgación autorizada por el Excmo. Ayuntamiento y de los trabajos realizados», Separata de Estudios Médicos, Núm. 45, p. 7.

16 LARA, E. de (1897), «La higiene en las minas de Linares», Industria minera, metalúrgica y mercantil, 37-38. 
nacionalidad francesa, y un capataz- y cuya historia clínica, publicada el mismo mes de abril, da cuenta de la participación en su tratamiento de Bonifacio de la Cuadra, a cuenta de su «modesto gabinete microbiológico» ${ }^{17}$. Por esas fechas se conoció que el Hospital de Úbeda atendía casos procedentes de las minas linarenses ${ }^{18}$. Pero tales noticias no generaron demasiada alarma, pues la Cartilla sanitaria publicada en 1901 por otro médico de Linares, Manuel Corral, empleado en la compañía de ferrocarriles MZA, no hacía mención alguna a este parasitismo. Si bien recomendaba el empleo de retretes portátiles en minas y talleres, dicha medida no es sino una más de las recomendaciones generales de higiene que ofrece.

Al regreso del Congreso Internacional de Higiene y Demografía de 1903, uno de los enviados oficiales españoles, Ángel de Larra y Cerezo, llamó la atención desde las páginas de Diario Universal (Madrid, 19 de octubre) sobre la necesidad de investigar la posible existencia en los cotos mineros hispanos de la parasitosis que tanto revuelo levantaba en Europa. Le contestó José Codina Castellví (1864-1934), jefe de sala del Hospital General de Madrid desde principios del mismo mes, informando sobre dos enfermos, procedentes de Linares y Ciudad Real, respectivamente, de los que poseía diagnóstico microscópico y cultivo de heces. El 28 de mayo siguiente, la Real Academia de Medicina de Madrid discutió la presentación por Codina de este problema, inaugurando un ciclo que continuó durante 1905 y 1906. En septiembre de 1904, el jefe del servicio médico de las Minas del Horcajo (Ciudad Real), Marciano González, dio cuenta en El Siglo Médico de nueva casuística propia, unos 30 casos que aseguraba haber tratado desde primeros de ese año, alertado por la lectura de prensa belga; es interesante conocer que se dirigió a la sección de bacteriología del Instituto Alfonso XIII, en particular a Antonio Mendoza, para conseguir asesoría en las técnicas microscópicas ${ }^{19}$. El mismo autor firma con el farmacéutico de su empresa, Juan González, un trabajo más amplio que recibió el premio de la Revista Iberoamericana de Ciencias Médi-

17 «La anemia por anquilostoma» (1897), Siglo Médico, 44 (n 2261), 266-267.

18 «Sesión del 8 de abril» (1905), Anales de la Real Academia de Medicina, 25, pp. 180-187.

19 GonzÁlez, M. (1904), «La anemia de los mineros y la anquilostomiasis», Siglo Médico, 51, 623-624. Antonio Mendoza había desarrollado colaboraciones similares desde tiempo atrás. En torno a 1888, y siendo a la sazón Jefe del Laboratorio histo-químico del Hospital San Juan de Dios de Madrid, colaboró con Ricardo Gómez de Figueroa en su estudio de la patología profesional de las Minas de Almadén, en particular de la anemia mercurial. En esta ocasión, Mendoza realizó análisis de sangre y técnicas histo-químicas con muestras procedentes de 26 mineros. Gómez de FigueroA, R. (1888), Estudio clínico de las enfermedades que padecen los obreros de las minas de Almadén, Madrid, Tip. de Manuel G. Hernández. 
cas en diciembre de 1904, si bien se publicó como folleto al año siguiente, constituyendo la primera monografía española sobre este asunto ${ }^{20}$. Su estructura se convirtió en la norma para otros estudios posteriores: historia de la enfermedad; historia natural del parásito; modos de contagio; profilaxis; clínica y diagnóstico; tratamiento. Ahora bien, la lógica que guiaba tanto la descripción como las propuestas era la propia de un profesional médico de empresa: prioridad a la recuperación de los enfermos, antes de que sufra su productividad e intervención médica a demanda, puramente individual: « [...] acudiendo antes de que haya perdido sus fuerzas, [el minero] puede seguir trabajando al mismo tiempo que atiende a su curación» ${ }^{21}$.

La conocida tesis de Eladio León Castro sobre higiene y patología mineras (Madrid, 1904; Almadén, 1907) hace referencia a la parasitosis siguiendo lo explicado por el ingeniero belga Paul Habets en una comunicación al Congreso internacional de Minería y Metalurgia de París (1900). Como quiera que esta propuesta sugería la realización universal de pruebas micrográficas durante tres meses entre los trabajadores de lugares sospechosos y León Castro no muestra experiencia propia alguna, podemos colegir que su trabajo profesional en el coto hullero de «El Porvenir de la Industria», en Fuente Ovejuna, posteriormente integrado en la poderosa Sociedad Minera y Metalúrgica de Peñarroya, no había seguido dichas recomendaciones ${ }^{22}$.

La zona minera jiennense fue objeto central de atención en las discusiones mantenidas en la Academia de Medicina madrileña. En la sesión del 8 de abril de 1905, el secretario de la misma, Manuel Iglesias, informó sobre una memoria remitida por Bonifacio de la Cuadra Martínez, del Hospital de Úbeda, que daba cuenta de que entre finales de 1896 y 1905 había conocido 62 enfermos de anquilostomiasis procedentes de las minas de Linares (Coto de la Luz, San Miguel, Arrayanes), siendo el primero un ingeniero, con siete falle$\operatorname{cidos}^{23}$. Este manuscrito contiene por vez primera un plan de profilaxis a gran escala, comprendiendo el reconocimiento obligatorio de los obreros, a fin de

20 GonzÁlez, M.; GonZÁLez, J. (1905), La anquilostomiasis o anemia de los mineros, Madrid, Est. Tip. Idamor Moreno.

21 GONZÁLEZ (1904), p. 17.

22 LEÓN y CASTRO, E. (1904), Un poco de higiene y patología mineras, Madrid, BaillyBaillière.

23 «Intervención del Secretario, Dr. Iglesias, leyendo un informe de la sección de Medicina (ponente, Manuel Iglesias) sobre la Memoria remitida a través del Dr. Alonso Sañudo, por D. Bonifacio de la Cuadra Martínez, residente en Úbeda, sobre Anquilostomiasis en mineros procedentes de Linares. Sesión del 8 de abril», Anales de la Real Academia de Medicina, 25, 1905, pp. 180-187. 
excluir del trabajo a los parasitados, la atención sanitaria de estos a cargo de los poderes públicos, el saneamiento de las minas afectadas, la instalación de letrinas y el reparto de una cartilla sanitaria. La intervención de Codina en la misma sesión académica, tras la lectura anterior, se inició con una puntualización muy pertinente, pues distinguió entre la enfermedad como problema de salud individual, que reclamaba curación, y su entidad como padecimiento colectivo, que exigía coartar su propagación con los medios de la higiene y, por tanto, la organización de una campaña o lucha sanitaria ${ }^{24}$. Es conveniente recordar la confluencia de ésta con propuestas similares acerca de la tuberculosis, las enfermedades venéreas o la mortalidad infantil, concebidas como tales problemas colectivos, o enfermedades sociales, en la España del momento $^{25}$. El conjunto de intervenciones de Codina ante la Academia durante 1905 se recogieron también en un folleto ${ }^{26}$. En esas páginas se plasmaba la experiencia del autor en el tratamiento de 50 casos, así como diversas consideraciones sobre el contagio, la profilaxis y la patogenia de la enfermedad, además de su perspectiva médico-social que exigía del gobierno la organización de una intervención a gran escala. Resulta característica la poca atención desde el mundo de la empresa por este problema, si observamos que la prime-

24 «Intervención del Sr. Codina» (1905), Anales de la Real Academia de Medicina, 25, pp. 188-197; 198-215.

25 Rodríguez OCAÑA, E. (1985), «Medicina y acción social», en C. López Alonso (ed.) De la Beneficencia al Bienestar Social. Cuatro siglos de acción social, Madrid, Siglo XXI editores, pp. 227-266. Rodríguez OCAÑA, E.; Molero MESA, J. (1993), «La cruzada por la salud. Las campañas sanitarias del primer tercio del siglo veinte en la construcción de la cultura de la salud», en L. Montiel (coord.) La Salud en el Estado de Bienestar. Análisis histórico, Madrid, Editorial Complutense, pp. 133-148; MEDINA DOMÉNECH, R. M.; RodRÍGUEZ OCAÑA, E. (1994), «Profesionalización médica y campañas sanitarias en la España del siglo XX», Dynamis, 14, 77-94; CASTEJón BoleA, R. (1997), «Los médicos de la Higiene. Medicina y prostitución en la España contemporánea (1847-1918)», Bulletin d'Histoire Contemporaine d'Espagne, núm. 25, 73-87; MOLERO MESA, J., «La lucha antituberculosa en España en el primer tercio del siglo XX», CAMPOS MARíN, R., «La lucha antialcohólica en España (1850-1923)» y RODRÍGUEZ OCAÑA, E., «La Higiene infantil», todos en: J. Atenza y J. Martínez (eds.) (2001), El Centro Secundario de Higiene rural de Talavera de la Reina y la sanidad española de su tiempo, Toledo, Junta de Comunidades de Castilla la Mancha, pp.131-147, 173-194 y 215233; Molero MesA, J.; MARTínez ANTONIO, F. (2002), «Las campañas sanitarias como paradigma de la acción social de la medicina», Trabajo Social y Salud, n 43 [monográfico «La acción social de la medicina y la construcción del sistema sanitario en la España contemporánea», coordinado por E. Perdiguero y R. Castejón], 119-148.

26 Codina, J. (1905), La anquilostomiasis (anemia de los mineros) en España. Comunicaciones a la Real Academia de Medicina, Madrid, Est. Tip. Viuda e Hijos de M. Tello, p. 7. 
ra noticia publicada por la Revista minera sobre esta enfermedad afirmaba que la ausencia de «atención especial por los médicos» indicaba la improbabilidad de la existencia de «grandes focos» de anquilostomiasis en las minas españolas ${ }^{27}$. Sólo daba cuenta de dos diagnósticos confirmados, los comunicados por Codina en su primera salida pública, además de recordar a los ingenieros fallecidos en Linares hacía años, por lo que es obvio que el anónimo redactor había manejado fuentes de información que ya estaban anticuadas.

La extensión de la preocupación por la anquilostomiasis en Europa actuaba, pues, de acicate para orientar la curiosidad de los médicos españoles hacia dicho padecimiento, a través de los congresos internacionales y de las publicaciones, como se observa en los trabajos que llevamos referidos. A ellas se sumó la procedente de Estados Unidos, que es pertinente comentar por separado por su singularidad.

Durante la última década del siglo diecinueve, la riquísima familia Rockefeller, propietaria de grandes negocios petrolíferos y mineros, imbuida de espíritu empresarial, se alejó de los actos caritativos para modelar su filantropía como una empresa encaminada a producir bienestar para la humanidad (empezando por la más cercana, la que habitaba los Estados Unidos de América). Sus primeras grandes manifestaciones fueron el General Board of Education y el Medical Research Institute (Nueva York), este último fundado en 1901. El principal consejero del patriarca John Rockefeller en esta tarea, Frederick T. Gates (1853-1929), atrajo la atención de su patrono sobre los asuntos médicos y de la salud, pues «si la ciencia y la enseñanza son el cerebro y los nervios de la civilización, la salud es su corazón» ${ }^{28}$. Para afrontar problemas básicos que obstaculizaban el progreso educativo en los estados sureños, y al mismo tiempo que se comenzaba la organización formal de una Fundación, los Rockefeller crearon una Comisión Sanitaria para Erradicar la Anquilostomiasis en 1909, cuyo principal ejecutivo fue un filósofo, experto en educación, Wickliffe Rose (1862-1931). Hasta 1913 Rose diseñó una notable campaña, que empezaba por un estudio epidemiológico (distribución, incidencia y prevalencia) y seguía por una campaña publicitaria para convencer de la existencia de la enfermedad, explicar los recursos que se le podían oponer y ganar el apoyo de la opinión pública y profesional. Una vez alcanzados

27 «ANQUILOSTOMASIA o anemia de los mineros (La). Información» (1905), Revista Minera, Metalúrgica y de Ingeniería [Madrid], 46, 3-5.

28 «If science and education are the brain and the nervous system of civilization [said Mr. Gates], health is its heart», citado en FosDICK, R. B. (1952), The Story of the Rockefeller Foundation, London, Odham Press, p. 39. 
estos objetivos, se actuaba a través de dispensarios volantes, expertos en microscopía e inspectores de saneamiento ${ }^{29}$. Además, incluyó la realización de una encuesta internacional a través de la cual estableció la dimensión global de la amenaza parasitaria. Hecho esto, Rose planteó que era ilusoria la defensa de un determinado país mientras existieran otros afectados, por la movilidad de las poblaciones y las relaciones internacionales. Al mismo tiempo, el éxito local de la intervención motivó la petición de auxilio desde otros países, lo que movió a crear una International Health Commission (en adelante, IHC) bajo el mandato de Rose, que en 1916 cambió su nombre a International Health Board (IHB) y, entre 1927 y 1951, al definitivo de International Health Division $(\mathrm{IHD})^{30}$. Como subraya Farley, todo en la dimensión transnacional de la Fundación Rockefeller comenzó por la anquilostomiasis — «hookworm was where it all started».

Con motivo de la encuesta internacional lanzada por la Comisión Sanitaria, se produjo una primera muestra de interés por España desde la Fundación. Su cuestionario llegó a Madrid en 1911 y le fue remitido a José Codina a través de la Academia de Medicina. Por propia confesión, sabemos que ese fue el estímulo que necesitó para realizar diversas pesquisas epidemiológicas con las que completó una monografía, significativamente titulada La anquilostomiasis ó anemia de los mineros como enfermedad social, especialmente en España (1912), que en 1914 envió a la IHC ${ }^{31}$. Al agradecerle su libro, Rose le ofreció actuar como corresponsal sobre el devenir de la anquilostomiasis en España, lo que Codina aceptó, si bien subrayando su voluntad de no enviar

29 FoSDICK (1952), pp. 46-49. Sobre la implicación de la Fundación Rockefeller, ver ETTLING, J. (1981), The Germ of Laziness, Cambridge, Mass., Harvard University Press; y (1990) «The role of the Rockefeller Foundation in hookworm research and control» en Schad G. A., Warren K. S. (eds.) Hookworm disease. Current status and new directions, Philadelphia, Taylor \& Francis, pp. 3-14.

30 Sobre Wickliffe Rose, el gestor que estableció el acuerdo con España, ver ACHESON, R. (1992), Wickliffe Rose of the Rockefeller Foundation: 1862-1931, Cambridge, Killicarn Press. Sobre la dimensión sanitaria de la Fundación Rockefeller, lo más reciente es el detallado estudio de Farley, J. (2004), To Cast Out Disease. A History of the International Health Division of the Rockefeller Foundation (1913-1951), Oxford, OUP, y el monográfico de Studies in the History and Philosophy of Biological and Biomedical Sciences, 2000, 31 (3), que han coordinado Ilana LöWY y Patrick ZYLBERMAN, con el título general de Medicine as a Social Instrument. Rockefeller Foundation, 1913-45.

31 Codina Castellví, J. (1912), La anquilostomiasis ó anemia de los mineros como enfermedad social, especialmente en España, Madrid, Eduardo Arias. Llama la atención que, aunque dicha relación se explicita en el texto, no se citan los trabajos de la Comisión Sanitaria norteamericana, ni siquiera en bibliografía. 
mas que datos oficiales ${ }^{32}$. En realidad dejó sin responder una pregunta directa del norteamericano, quien se interesó por los resultados de la legislación de 1912, de la que hablaremos enseguida, y la corresponsalía no tuvo más consecuencias.

Con esta aportación monográfica de Codina podemos cerrar la primera época hispánica de la uncinariasis. Con ella se dispuso de una exposición actualizada de los conocimientos existentes sobre la biología del parásito, así como sobre el diagnóstico, clínica y tratamiento de la parasitosis y de los esfuerzos que se realizaban en el mundo frente a ella. A la vez, ofrece la primera aproximación sistemática a su distribución por España, conseguida a través de encuestas e inspección personal de la zona más preocupante a tenor de lo conocido hasta entonces, los cotos mineros de la provincia de Jaén.

La contribución de Codina ha de entenderse como un deseo de movilización de la opinión pública [en el sentido elitista con que el autor se dirigía a «las clases directoras» y «profesionales»] en torno a uno de los riesgos nuevos que, conjuntamente, la extensión de la industria extractiva y el desarrollo de la noción etiológica de los gérmenes vivos generaba en la sociedad española del siglo XX. El riesgo se configuraba como auténtico "peligro de hecatombe», desde las palabras iniciales de la monografía, como «azote de ciertas profesiones mecánicas [y] calamidad patológica de extensas regiones y de países enteros», al punto que merecía la consideración de enfermedad social. Y para que quedara claro la comparó con la tuberculosis, nada menos ${ }^{33}$.

La parte original de este estudio consiste en una investigación epidemiológica rudimentaria, compuesta por entrevistas con unos 60 mineros ingresados en su hospital, procedentes de la cuenca jiennense, una encuesta circulada a médicos de minas de Asturias y Vizcaya, así como una visita personal del autor a la zona minera jiennense. El protocolo de entrevista incluía preguntas referidas a la historia personal y laboral de cada minero así como a las condiciones higiénico-sanitarias de su trabajo. La encuesta buscaba conseguir datos globales de empresas, trabajadores y afectados, tipo de mineral y medidas de higiene empleadas. Las contestaciones mostraban un gran espectro de situaciones, sobre la base de una implicación laboral desde edades muy tempranas; hallaba minas infectadas en Jaén, Ciudad Real, Córdoba, Murcia y Asturias, con porcentajes estimados de entre el 2 y el $25 \%$ de su población trabajadora.

32 Rose a Codina, 21-11-1916, Rockefeller Archive Centre (RAC), Rockefeller Foundation collection (RF), Record Group 5, Series 1.2, Box 37, Folder 582. Codina a Rose, 3-1-1917, RAC, RF, 5, 1.2, 56, 819 .

33 Codina (1912), p. 25. 
En ningún caso existían retretes en el interior de las explotaciones, ni lavabos, ni se retiraban los excrementos en vasos herméticos.

Finalmente, Codina planteaba la necesidad de articular una campaña específica, empezando por la realización de un mapa completo del padecimiento, a partir de la implantación obligatoria del examen de heces para todos los solicitantes de trabajo y todos los mineros sospechosos de padecer la parasitosis, instalando un laboratorio en cada cuenca. Las restantes medidas son similares a las ya imaginadas por De la Cuadra en 1905 — que no eran sino las habituales en los países cercanos, conocidas a través de las publicaciones foráneas y las reuniones internacionales - y que completaba con dos sugerencias, establecer un carnet sanitario personal, para certificar la ausencia de huevos de anquilostoma tras exámenes microscópicos realizados en tres días consecutivos, e incluir la anquilostomiasis entre los accidentes del trabajo, como vía de protección social para los afectados. Esta tesis ya la había expuesto el autor ante la Real Academia de Jurisprudencia y Legislación en junio de 1905, al calor de un discurso anterior de Canalejas, en cuyo gobierno confiaba entonces para que colocara «la higiene social como base para la reconstrucción del estado ${ }^{34}$ — confianza que había quedado defraudada tras el efectivo ejercicio de la Presidencia de Gobierno por aquél.

2. LA INSPECCIÓN DE SANIDAD DEL CAMPO. PRIMEROS PASOS EN LA LUCHA CONTRA LA ANQUILOSTOMIASIS EN ESPAÑA

Una de las medidas abordadas desde una óptica reformista en el cambio de siglo, en la estela racional de esa higiene social que acuciaba a los espíritus preocupados por el bienestar de la nación, fue la creación, en 1910, de una Inspección de Sanidad del Campo. Pertenecía al organigrama de la Dirección General de Agricultura, Minas y Montes y mantuvo su actividad hasta octubre de 1918, bajo la jefatura de Antonio Muñoz (médico del Hospital de la Princesa). Nuestro conocido Bonifacio de la Cuadra ocupó uno de los once puestos de inspectores regionales con que se dotó este organismo. Que su fundamento era claro y tenía conexión con problemas reales de la vida rural hispana es algo que se desprende del enunciado de sus objetivos primeros, tal como los expuso la R.O. del Ministerio de Fomento de 14 de julio de 1911: estudio del paludismo, aguas potables y enfermedades que se relacionan con la contaminación hídrica, alimentación de los obreros del campo y enferme-

34 Codina (1912), p. 124. 
dades derivadas de su alteración, fiebre de malta y anquilostomiasis (además de que prometía abordar en el futuro los problemas de la vivienda y de otras actividades laborales y culturales). Para afrontar dicho programa de trabajo se prepararon cuestionarios relativos a cada uno de los aspectos a estudiar, cuya respuesta habían de recabar los inspectores regionales a través de los médicos titulares o los de minas, en su caso. Sin embargo su actividad práctica apenas sobrepasó, aparte de lo que aquí se cuenta, la recogida de la información sobre aguas y paludismo ${ }^{35}$.

El libro de Codina incluyó la respuesta al cuestionario sobre anquilostomiasis relativa al distrito de Linares, único realizado durante la primera ronda inspectora, celebrada entre octubre y noviembre de 1911, así como un artículo de Bonifacio de la Cuadra sobre dicha visita publicado en el Boletín de Agricultura de noviembre de $1911^{36}$.

El informe sobre la zona minera en cuestión señalaba que los médicos de la zona sólo estudiaban los aspectos clínicos de la anquilostomiasis, por falta de laboratorios micrográficos, así como que no se ponían en práctica medidas de profilaxis, ni individual (limpieza corporal, calzado) ni colectivas (detección de portadores y análisis periódico de los mineros, retretes en el interior, etc.).

Familiarizado Muñoz con la enfermedad, gracias a su práctica hospitalaria, los resultados de esta inspección le llevaron a sustentar la hipótesis de una prevalencia elevada de la anquilostomiasis y la necesidad consiguiente de una intervención gubernativa sobre las empresas mineras para controlarla, mientras que se procedía a verificar aquella. Convencido el ministerio, a comienzos de 1912 se dictó una nueva R.O. de Fomento (3 de enero de 1912; Gaceta del 22), como primera disposición legal sobre profilaxis de tal condición. Las medidas seguían las líneas que ya conocemos; ordenaba que no se admitiera ningún obrero nuevo sin previo reconocimiento de heces; que no se permitiera trabajar en el interior a los parasitados; prohibía, bajo despido, defecar en túneles y galerías; y obligaba a instalar retretes en el interior y lugares de aseo en el exterior de las explotaciones. Así mismo dispuso de nuevo que por los inspectores de Sanidad del Campo se practicaran visitas de reconocimiento a las zonas mineras sospechosas.

El reglamento general de la entidad sanitaria - característicamente dictado con casi un lustro de retraso desde la constitución de la misma - estableció

35 INSPECCIÓN DE SANIDAD DEL CAMPO (1918), Avances de los inventarios de Paludismo y Aguas Potables. Datos remitidos por los Inspectores Regionales. Madrid, Ministerio de Fomento. Dirección General de Agricultura, Minas y Montes.

36 CODINA (1912), pp. 145-156. 
medidas concretas para realizar la estadística de la anquilostomiasis (R.D. de 8 de agosto de 1916, Gaceta del 11). En el mismo número del Diario oficial, una nueva R.O. del Ministerio de Fomento (9 de agosto) reiteraba lo dispuesto en 1912, añadiendo dos aspectos interesantes: la obligación de las empresas de atender a sus obreros enfermos y la habilitación de un laboratorio en cada distrito minero, a disposición de los inspectores de Sanidad del Campo y el auxilio de los médicos de minas, en el que efectuar los diagnósticos y los tratamientos, además de realizar tareas de educación sanitaria. Esto se concretaba en el establecimiento de sanatorios, costeados por las empresas y regidos por la inspección sanitaria indicada.

La reiteración de una disposición ya indica la falta de cumplimiento. La orden de 1912 abrió un nuevo frente de confrontación en el complicado mundo de la minería, entre obreros, empresarios y autoridades locales. Si la visita del inspector de la Cuadra a las minas de Linares-La Carolina en el otoño de 1911 estimó la existencia de un 10\% de infectados entre los obreros destinados a trabajos de interior, los médicos de las empresas entregaron al año siguiente a otro Inspector de Minas, el ingeniero Sierra en este caso, un escrito firmado negando la existencia de caso alguno entre sus obreros ${ }^{37}$. Por aquellas fechas, recordó algunos años después otro práctico, el desgaste del trabajo minero era terrible, produciendo la muerte en sujetos que rara vez alcanzaban los 40 años, «en estado lamentabilísimo de agotamiento» ${ }^{38}$. Y aunque fuera cierta (aunque improbable) la ausencia de parasitados en un momento determinado, la gran movilidad de la población minera, la escasez de recursos higiénicos y la falta de controles sanitarios hacían inevitable la propagación de los parásitos. Una nueva visita de Bonifacio de la Cuadra, en agosto de 1916, motivó que la Junta local del Instituto de Reformas Sociales (IRS) solicitara la intervención de la Sección segunda, misión realizada por José Úbeda Correal en febrero de 1917.

El Dictamen que presentó este último mostraba la aguda contradicción entre la prohibición de trabajar a ciertas personas, por un diagnóstico médico, y

37 ÚBeda CORREAl, J. (1917), Dictamen referente á una información acerca de la anquilostomiasis efectuada... en La Carolina (Jaén), Madrid, Instituto de Reformas Sociales, pp.7-8.

38 TorRes Fraguas, J. (1928), La anquilostomiasis como enfermedad profesional: comunicación presentada al V Congreso Internacional para Accidentes del Trabajo, Madrid, Publicaciones de «Anales de la Beneficencia Municipal» imp. Juan Pérez Torres, p. 4: «nosotros recordamos que en las minas de Hiendelaencina raro era el obrero que trabajaba en el interior que llegaba a los 40 años, muriendo la mayoría entre los 30 y los 35 años en estado lamentabilísimo de agotamiento». 
el éxito de cualquier campaña de erradicación. Por un lado, los afectados dentro de las plantillas mineras dejaban de percibir una parte considerable de sus emolumentos, pues el salario se sustituía por un subsidio de cuantía variable, pero siempre escasa, cuya entidad exigían los obreros que fuera idéntica a la recibida en caso de accidente laboral. Por otra, las empresas presionaban para la más pronta reincorporación al trabajo de los subsidiados, frente a la norma de no darles ocupación en el interior mientras existieran análisis positivos de heces y la realidad de unos tratamientos largos y de éxito muchas veces problemático. Por último, estaba el pavoroso problema de los enfermos no empleados, a quien nadie ayudaba expresamente y que veían frustradas sus oportunidades de colocación en el medio minero, por lo que buscaban por cualquier medio burlar las barreras diagnósticas, algo factible en momentos de apremio productivo como fueron estos años coincidentes con la Guerra Mundial. El grado de cumplimiento de las disposiciones higiénicas, además, era distinto según las empresas, en función de argumentos de tipo económico; y no hay que descartar el empleo disciplinario de algunas de las normas sanitarias: por ejemplo, en la mina Los Guindos, dos días antes de realizarse la visita de Úbeda, se había producido el despido de un relevo completo (varias decenas de trabajadores, puede que más de un centenar, pues la empresa tenía una plantilla superior a 800 hombres) supuestamente por infringir la norma de no defecar en el interior.

En el agitado contexto minero de los años de la Guerra Mundial, con un incremento notable de la producción y de las ganancias en primera instancia, momento seguido por otro de crisis notable, esta irregularidad de la aplicación de la normativa sanitaria que mostraban los datos anteriores no podía sino extenderse. Tres compañías de la zona de La Carolina (Los Guindos, Sociedad de Peñarroya y Centenillo) emprendieron la aplicación de las disposiciones oficiales entre 1916 y 1919, si bien sólo El Centenillo (en realidad, la empresa, inglesa, se llamaba New-Centenillo Silver Lead Mines Co. Ltd.) la mantuvo en fechas posteriores, a cargo del médico Guillermo Sánchez Martín $^{39}$. La campaña, consistente en el reconocimiento obligatorio de todos los

39 SÁNChez MARTín, G. (1921), «La anquilostomiasis en Linares y La Carolina», Revista Minera, Metalúrgica y de Ingeniería, 72, [fascículos de 16 y 24 de septiembre, de 1 de octubre y de 8 de noviembre]; SÁNChEz MARTín, G. (1923), «Otra vez la anquilostomiasis», Revista Minera, Metalúrgica y de Ingeniería, 74, 177-179; SÁnChEZ MARTín, G. (1923), «La anquilostomiasis en las minas de "El Centenillo", España», Siglo médico, 71, 332-335; 361365; 390-392. MARTínez OrTIZ, J. J.; TARIFA FERnÁNDEZ, A. (1999), Medicina social, demografía y enfermedad en la minería giennense contemporánea. El Centenillo: 1925-1964, Jaén, Diputación Provincial de Jaén. 
solicitantes de trabajo, más el tratamiento de los empleados afectados y la desinfección del interior de las minas mediante soluciones salinas concentradas, comenzó detectando cifras cercanas al $60 \%$ de parasitados, que para 1920 se habían reducido a un 20\%, para volver a acercarse al $50 \%$ en junio de 1921, lo que el mencionado médico lamentó como una oportunidad fallida por parte de unos poderes públicos que no supieron aprovechar el tirón de ese esfuerzo empresarial. Otras fuentes hablaron de repuntes de hasta el $78 \%$ de afectados en algunas explotaciones, a consecuencia del abandono del tratamiento pagado que había existido durante los años de guerra ${ }^{40}$. Sánchez Martín subrayó la movilidad de dicha población, como advertencia para sus colegas de las cuencas asturianas, afirmando que muchos de los que marcharon a trabajar en ellas en 1916 eran «portadores del gusano». Este concepto cobra importancia sólo en un contexto de profilaxis tendente a la erradicación, como ha mostrado el trabajo ya comentado de Ilana Löwy, y está ligado exclusivamente al dominio de la práctica de laboratorio, puesto que en ningún momento se nos aclara el estado clínico de los sujetos así etiquetados ${ }^{41}$. En las Minas del Centenillo, la vigilancia continuada había sido capaz de producir la erradicación temporal de la anquilostomiasis, a costa del rechazo de cientos de aspirantes a empleo y de la aplicación de un tratamiento resolutivo, o «medicación completa del Centenillo» con el que se conseguía la curación de los afectados en el plazo más corto, según la experiencia del hospitaldispensario de aquella mina (sólo 11,23 días de media, menos de la mitad de la duración más habitual). Es una experiencia relevante, de acuerdo con la interpretación que el médico hacía de este padecimiento como «nosohemia parasitaria que, al empobrecer orgánicamente a la masa obrera que laborea las minas, reduce su coeficiente de capacidad productora $\rangle^{42}$. Bien es cierto que en coyunturas con escasez de mano de obra, hubo que relajar las medidas de selección de trabajadores y admitir cifras importantes de mineros infectados. Así lo refleja una comunicación de los responsables locales de la explotación a los directivos de Londres fechada en septiembre de 1919, en la que se estimaba en un 90\% el porcentaje de afectados en el distrito, excepción hecha de sus propios obreros. En cualquier caso, sólo se admitían individuos con bajo nivel de afectación y que acreditaran ser first class miners (importante matización del concepto de «portador») siendo despedidos a la primera oportunidad en caso contrario. Este argumento, junto a la alusión al elevado nivel de cumplimiento de

\footnotetext{
40 TORRES Fraguas (1928).

41 LÖWY (2003).

42 SÁNCHEZ MARTín (1923), p. 332.
} 
las normas de interior y a la eficaz labor curativa de los servicios médicos, parecía destinado a disipar los recelos expresados desde Londres ${ }^{43}$.

El sustituto de Sánchez Martín como médico de El Centenillo, González Comino, reconocía la importancia de los tratamientos resolutivos, puesto que la duración del mismo estaba limitada por la presión empresarial, que no gustaba de ver como «se eternizaban» sus obreros en la enfermería. Sin embargo, reveló un no pequeño problema de la llamada «medicación completa»: si su aplicación era más corta, también era más fastidiosa, hasta el punto que generaba una tremenda resistencia a repetirlo en los afectados que presentaban un parasitismo de mediana intensidad, que requería dos o más tandas de tratamiento seguidas ${ }^{44}$. La razón principal a la que Sánchez Martín achacaba la falta de una intervención médica más eficaz era el pequeño tamaño de las explotaciones mineras, que impedía la dotación de médicos; de hecho, para cumplir la legislación de accidentes, sólo se contrataba la curación de los heridos con el médico del pueblo más próximo ${ }^{45}$. Este argumento se tendrá en cuenta, como veremos, en la etapa siguiente.

3. LA ORGANIZACIÓN DE LA LUCHA CONTRA LA ANQUILOSTOMIASIS. LA INTERVENCIÓN DE LA FUNDACIÓN ROCKEFELLER.

Las Minas del Centenillo mantuvieron una actitud beligerante contra «el gusano de las minas» durante la primera mitad de la década de 1920, parcialmente secundada por la sociedad Los Guindos, de capital alemán, como única muestra conocida de preocupación hasta la incorporación de la Fundación Rockefeller en España. El contacto entre ésta y el Gobierno de España hasta la firma de un convenio de colaboración en 1922, y sus consecuencias, se encuentran expuestos en otros trabajos ${ }^{46}$. El convenio marcaba dos fases: en

43 ARCHIVO HISTÓRICO PROVINCIAL DE JAÉN, Sección Minas del Centenillo, Libros copiadores de cartas, leg. 16462, pp. 242-243.

44 GonZÁlez Comino, J. A (1926), «Campaña sanitaria. La anquilostomiasis, o anemia de los mineros», Diario regional, La Carolina c. núm 312.

45 SÁNCHEZ MARTín (1923), p. 333.

46 Rodríguez Ocaña, E.; Bernabeu Mestre, J.; Barona, J. L. (1998) «La Fundación Rockefeller y España, 1914-1936. Un acuerdo para la modernización científica y sanitaria», en J. L. García, J. M. Moreno, G. Ruiz (coords.) Estudios de historia de las técnicas, la arqueología industrial y las ciencias. VI Congreso de la Sociedad Española de Historia de las Ciencias y de las Técnicas, Segovia-La Granja, 1996, Salamanca, C. de Cultura de la Junta de Castilla y León, vol. 2, pp. 531-539; RODRíGUEZ OCAÑA, E. (2000), «Foreign Expertise, Poli- 
un primer momento se enviaría un sanitario cualificado para acometer un estudio sobre la extensión de la anquilostomiasis en España y proponer medidas para su erradicación; la segunda fase, facultativa en función de la marcha de la primera, consistiría en una actuación piloto de Salud Pública integral en una zona a determinar ${ }^{47}$. Se preveía también la dotación de becas para profesionales españoles. Si bien para los altos responsables sanitarios la anquilostomiasis aparecía como un problema menor, de entre los tres (tuberculosis, anquilostomiasis y paludismo) señalados por Castillejo en la carta que solicitaba expresamente la ayuda de la Fundación Rockefeller, era el que a esta resultaba más fácil de abordar ${ }^{48}$. Recordemos que, en 1921, la IHB estaba presente como asesora en campañas contra la anquilostomiasis en 41 países, y se calculaba que había practicado cuatro millones de exámenes fecales y tratado dos millones de $\operatorname{casos}^{49}$.

La condición de objetivo táctico que revestía esta lucha no resultó ajena al personal español activo en salud pública, que coincidió con aquélla en su visión preventiva-educativa como medio de adquirir completa legitimidad social. Así lo expresó de forma rotunda en escritos y conferencias de 1927-28 Emilio Luengo, una de las personas del entorno de Pittaluga, que ocupó distintos puestos en el Instituto Nacional de Higiene y en la campaña antipalúdica que comenzó en 1921. Según él, la IHB eligió la anquilostomiasis, no por su gravedad ni prevalencia, sino porque «se diagnostica con certeza absoluta fácilmente por medio del laboratorio; puede curarse también con facilidad $[\ldots]$ y $[\ldots]$ puede evitarse, con garantía completa de éxito [mediante] el establecimiento de retretes adecuados y su uso» ${ }^{50}$. Este éxito producirá «la aparición de un sentimiento popular a favor del establecimiento de servicios permanentes encargados de la labor higiénico-sanitaria general de una comunidad» ${ }^{51}$.

tical Pragmatism and Professional Elite: The Rockefeller Foundation in Spain, 1919-39», Studies in History and Philosophy of Biology and Biomedical Science, 31 (3), 447-461; (2000), «La intervención de la Fundación Rockefeller en la creación de la sanidad contemporánea en España», Revista Española de Salud Pública, 74 [n $\mathrm{n}^{\circ}$ monográfico, Centenario de Marcelino Pascua Martínez, 1897-1977], 27-34.

47 Request from the Government of Spain, p. 4. RAC, RF, 5, 1.2, 148, 1959. Como se justifica en el trabajo presentado ante el Congreso de Segovia, esta estrategia, habitual en los planes de la IHB, resultó coincidente con lo propuesto independientemente por José Castillejo, el principal interlocutor hispano en las negociaciones.

48 Castillejo a Rose, 6-02-1922, RAC, RF, 5, 1.2, 148, 1959.

49 Bibliography (1922), p. XXIII.

50 Luengo, E. (1927), «La conquista de la anquilostomiasis», Siglo médico, 79, 611-614 ; 80, 351-353; y (1928), 81, 54-57 (cita de p. 352).

51 LuENGO, E. (1928), La anquilostomiasis en las minas españolas, Madrid, s.i., pp. 23-42 (cita de p. 36); (1928b), «Conferencia en la Escuela de Minas», Revista Minera, Metalúrgica y 
Bajo tal sobrentendido inició sus trabajos en España un enviado de la IHB, curtido en misiones anteriores en América Central, Charles A. Bailey (nac. 1876) ${ }^{52}$. Residió en España entre diciembre de 1924 y junio de 1926, y se siguió ocupando de los asuntos españoles al menos hasta 1929. De inmediato se dedicó a visitar a las autoridades y personas relevantes, a fin de preparar su investigación en las comarcas mineras después que pasaran las fiestas navideñas.

Mientras esperaba la llegada del material que le había sido remitido desde Nueva York, se dedicó a recorrer las zonas mineras y entrar en contacto con autoridades, médicos y empresarios. Visitadas Jaén, Córdoba y Sevilla, advirtió que no existía conciencia alguna de alarma sobre este problema, ni a nivel popular ni empresarial ni entre los médicos; algo más adelante se percató de que Murillo, el Director General de Sanidad, tampoco tenía el más mínimo interés por el tema, hasta el punto de que ni siquiera le agradecía el que periódicamente le diera cuenta de la marcha de sus trabajos ${ }^{53}$. Esta impresión fue confirmada por el parasitólogo francés E. Brumpt, que visitó España entre agosto y septiembre de 1925 con la Comisión internacional de Paludismo ${ }^{54}$.

La Dirección General de Sanidad asignó para colaborar con Bailey al jefe de la Brigada Sanitaria Central, Antonio Ortiz de Landázuri (junto a Julio de Prada y Donato Fuejo García, becado en Estados Unidos por la Fundación entre 1923 y 1924), además de a Diego Hernández Pacheco, médico recién licenciado, y el estudiante de último curso Francisco Oquiñena, ambos del grupo vinculado al laboratorio de Parasitología de la Universidad madrileña (y que ya había participado en la campaña antipalúdica oficial). La colaboración discurrió de forma algo tormentosa. En junio, el jefe de la oficina europea de la IHB manifestó que Ortiz no cumplía bien en el trabajo de laboratorio (su desempeño era far from satisfactory) y que quería abandonar ${ }^{55}$. A mediados de agosto, Bailey cuenta que él mismo había tenido que realizar 9 de cada 10 recuentos de huevos en heces, de un total de más de 6.800 análisis, así como la mayor parte de la preparación de muestras de tierra, pues resultaba que este tipo de manipulaciones no eran agradables para los españoles ${ }^{56}$.

de Ingeniería, 79 (núm. 3.115), 165-170 (cita de p. 168). Prácticamente, parafrasea las ideas de W. Rose, tal como las recoge FARLEY (2004), pp. 2-6.

52 RodríGuez OCAÑA, E. (2001), «El Informe sobre la sanidad española (1926) de Charles A. Bailey, enviado de la Fundación Rockefeller», Cronos. Cuadernos Valencianos de Historia de la Medicina y de la Ciencia, 4 (1-2), 63-79.

53 Gunn a Russell, 9-06-1925, RAC, RF, 5, 1.2, 238, 3061.

54 Gunn a Russell, 11-09-1925, RAC, RF, 5, 1.2, 238, 3059.

55 Gunn a Russell, 9-06-1925, RAC, RF, 5, 1.2, 238, 3061.

56 Bailey a Russell, 17-08-1925, RAC, RF, 5, 1.2, 238, 3061. 
Que esto no era una percepción exagerada lo demuestra la experiencia posterior del médico director del Hospital minero de Triano, que se topó con el mismo problema con motivo de una investigación llevada a cabo en minas de Vizcaya y Santander en 1932, hasta el punto que su personal amenazó con ponerse en huelga ${ }^{57}$. Además, parece que a Antonio Ortiz salir de Madrid para estar más de una o dos semanas en el campo le resultaba difícil de soportar ${ }^{58}$.

A partir de abril de 1925, dicho grupo visitó 27 minas de las provincias de Jaén, Sevilla, Córdoba, Huelva, Ciudad Real, Murcia, Vizcaya, Santander y Baleares. En diciembre redactó Bailey su informe, que envió a la IHB y a la Dirección General de Sanidad, para su publicación en sus respectivas revis$\operatorname{tas}^{59}$. De los 9.149 mineros examinados resultaron positivos 2.427 , con un grado de infección medio o bajo, pues el $65 \%$ albergaban menos de 25 gusanos (estimados a partir del recuento de huevos en heces). La infección se concentraba en las minas de plomo y de carbón (alrededor de un $40 \%$ de afectados), siendo inexistente en las minerías del cobre y del hierro. La coincidencia de hallarse en todas las minas obreros con grados altos de infección, la inexistencia de retretes de interior y la gran trashumancia poblacional llevaba a calcular la existencia en todo el país de alrededor de 10.000 mineros afectados, cuya productividad se vería reducida en una cuarta parte.

Las recomendaciones profilácticas eran simples y reiteraban las ya expuestas desde 1905, pero con la concreción que procedía de la experiencia de su principal autor, a saber: evitar la contaminación del suelo con excretas humanas; examen y tratamiento de cada minero hasta su curación completa; y

57 Fidalgo Tato, V. (1933), Investigación de los anquilostomas en las minas de Vizca$y a$, Bilbao, impr. Zoila Ascasíbar: «No resulta grata la inspección natural de la materia objeto de examen...», da cuenta de la producción de trastornos físicos al personal del laboratorio, amenaza de plante y necesidad de rotación del personal, pp. 41-45.

58 Bailey a Russell, 17-08-1925, RAC, RF, 5, 1.2, 238, 3061.

59 Gunn a Russell, 23-12-1925, RAC, RF, 5, 1.2, 238, 3059. BAILEY, C. A. (1926), «Hookworm Survey of the Mines of Spain», The Bulletin of the International Health Board, 6 (3), 191297. «La anquilostomiasis en las minas de España». Boletín técnico de la DGS, $\mathrm{n}^{\circ} 1$. Fue reproducido o extractado, total o parcialmente, en varias otras publicaciones, como: «La anquilostomiasis en las minas de España. Relación de los trabajos realizados bajo la dirección técnica del Dr. Charles A. Bailey, director en España de la International Health Board, en colaboración con el Dr. Ortiz de Landázuri, jefe de la Brigada sanitaria central de la Dirección general de Sanidad» (1926), Revista Minera, Metalúrgica y de Ingeniería, 77 (1 de abril, $\mathrm{n}^{\circ}$ 3018), 181-184; 197-200. «Primer informe sobre la anquilostomiasis en las minas de Linares (Jaén), por el comisionado del Instituto Rockefeller Dr. Bailey» (1927), Medicina Ibera, 21/2 (16 de junio, $\left.n^{\circ} 506\right)$, LI-LIII. 
examen preventivo micrográfico para todos los solicitantes de trabajo. Para garantizar el cumplimiento de estas disposiciones, y otras que tenían como fin evitar el transporte de parásitos al mundo exterior (instalación de lavabosvestuarios, información a la población obrera), el Informe sugería establecer un plan de lucha, incluyendo la designación de un Inspector sanitario que vigilara su puesta en práctica.

En efecto, el Real Decreto Ley de 12 de mayo de 1926 (Gaceta del 13 de mayo) aceptó las recomendaciones expertas. Dispuso la obligación de realizar análisis de heces a toda la población minera, repetidos anualmente, así como a los solicitantes de trabajo, obligaba a instalar laboratorios para núcleos de al menos 1.000 obreros, aportados por una o varias empresas, que debían correr con el coste de los tratamientos y los jornales completos mientras durasen aquellos y estipuló también la obligatoriedad de establecer medios higiénicos para disponer de las heces, efectuar el drenaje de las galerías y evitar la contaminación (dotación de salas de comer y de aseo). Se precisaba que los médicos encargados de realizar estos reconocimientos debían contar con una formación específica, obtenida mediante la asistencia a un curso oficial. Y disponía la creación de un inspector especial, de Sanidad minera, para vigilar el cumplimiento de las normas en colaboración con los provinciales de Sanidad, cargo para el que se nombró a Diego Hernández Pacheco.

La IHB ofreció suplementar el sueldo del Inspector y hacerse cargo de sus gastos de transporte, abonando mensualmente 333,33 ptas para sueldo y hasta 500 para viajes a cambio de que el gobierno le pagara no menos de 500 ptas al mes. Este acuerdo tenía otras dos condiciones, el puesto oficial tendría dedicación exclusiva y el gobierno español se haría cargo del total de gastos a partir de $1928^{60}$.

Una vez promulgado el decreto, existieron contactos entre ingenieros y representantes de compañías mineras con las autoridades sanitarias. El trabajo inicial del Inspector consistió básicamente en pactar con las empresas los medios de cumplir el decreto de lucha, que se formalizaron en un Reglamento de aplicación de esta ley (Gaceta de 9 de diciembre de 1926) ${ }^{61}$. Para empezar,

60 Bailey a Gunn, 22-03-1926, enviada a Russell, 9-04-1926, RAC, RF, 5, 1.2, 273, 3464. Copia de las cartas cursadas entre Bailey y el Ministerio de Gobernación a fecha 22-05-1926 y 24-061926, respectivamente, reproducidas en Bailey a Russell, 10-08-1926, RAC, RF, 5, 1.2, 273, 3461.

61 «R.O. aprobando el Reglamento para la aplicación del RD de 12 de mayo pasado sobre anquilostomiasis» (1927), Revista Minera, Metalúrgica y de Ingeniería, 78, 88-91. Sobre los contactos de Hernández Pacheco con empresas, Bailey a Gunn, Memorandum, 11-11-1926, en Bailey a Russell, 3-11-1926. RAC, RF, 5, 1.2, 273, 3463. 
se diferenciaba entre minas exentas e infectadas, con lo que las primeras quedaban eximidas de muchas de las obligaciones sanitarias: sólo tenían que tratar a los obreros que entraran infectados, pero por cuenta de la empresa de la que procedieran si habían transcurrido menos de 3 meses de su llegada. Se entiende que esta categoría englobaría a aquellas cuyo medio físico resultaba hostil a la supervivencia de las larvas (caso de la minería del cobre o del hierro), si bien otras podían alcanzarla gracias a una campaña sanitaria mantenida. Una vez dentro de ese grupo, estas minas eran las únicas que tendrían la potestad de negar empleo a solicitantes parasitados. El grupo de las minas infectadas era el que debía aplicar todo el conjunto de disposiciones profilácticas, además de procurar la instalación de centros de reconocimiento micrográfico, que eventualmente podrían formar laboratorios regionales, a cargo de médicos especialistas, distintos de los de accidentes (salvo en el caso de una ubicación aislada de la explotación). Se permitió descontar un $25 \%$ de los sueldos para pagar los tratamientos, mientras que se estipulaba que el tiempo de aseo, práctica que se convertía en obligatoria para los trabajadores al abandonar el tajo, no computaba como jornada laboral. Los obreros parasitados que rehusaran tratamiento serían despedidos sin indemnización; a cambio, un diagnóstico previo de anquilostomiasis no podía ser motivo de inadmisión. Las faltas contra la legislación protectora se convertían en atentados contra la salud pública, castigadas con multas de entre 50 y 500 pesetas, según el reglamento de Sanidad municipal de 1915. También se extendió la competencia de la inspección a aquellas obras públicas y privadas, industrias y labores agrícolas susceptibles de contribuir a esta parasitosis.

A mediados de noviembre de 1926, Bailey era abiertamente optimista sobre la buena marcha de la campaña ${ }^{62}$. Se mantenían las actuaciones en las minas públicas de Arrayanes, bajo la supervisión directa de Hernández Pacheco, donde se había habilitado un laboratorio, instalado un pabellón para lavado y cambio de ropa (con seis duchas, dos bañeras y armarios ropero) así como 80 letrinas portátiles en el interior, con un personal fijo de mantenimiento. El tratamiento de los afectados se llevaba a cabo en el Hospital municipal de Linares, ya que el internamiento era necesario para evitar que bebieran alcohol - porque interfería con los fármacos suministrados -; la empresa pagaba 4 ptas/día al hospital por cada minero tratado y estos conservaban el $75 \%$ de su paga esos días. También en Linares-La Carolina se había producido una reunión entre 10 ó 12 minas privadas para ponerse de acuerdo en crear

62 Bailey a Gunn, Memorandum, 11-11-1926, en Bailey a Russell, 3-11-1926. RAC, RF, 5, $1.2,273,3463$. 
un laboratorio centralizado (con un médico, un practicante, dos celadores y un administrador a tiempo parcial) del que correrían con los gastos a escote, según el número de mineros examinados y tratados. Este anunciado laboratorio regional abrió en febrero de 1927, y en sus primeros ocho meses de vida había examinado a 2.719 mineros y tratado a 220 . El informe anual de la New-Centenillo Silver Lead Mines correspondiente a 1927 reflejaba el éxito de las medidas adoptadas desde comienzos de la década. En los exámenes practicados a sus trabajadores a comienzos de dicho año sólo se detectaron seis casos leves que respondieron bien al tratamiento. En consecuencia, las Minas del Centenillo fueron declaradas oficialmente exentas de enfermedad, categoría que según el informe sólo alcanzó esta explotación ${ }^{63}$.

Durante 1927 comenzaron los cursos de formación, organizados de acuerdo con los respectivos Institutos provinciales de Higiene y dirigidos por el Inspector de sanidad minera, en Linares, Córdoba, Sevilla, Huelva (aquí no intervino el inspector) y Puertollano, con una asistencia total de 56 médicos, cuatro farmacéuticos y dos veterinarios. Las visitas a las zonas mineras incluían la organización de exámenes generales de la población minera (se realizaron más de 28.500 análisis de heces en ese año) y la instalación de letrinas en los sitios que indicaba el inspector. La medida menos seguida era la de instalar servicios de aseo, pues, como indicaba el propio Hernández Pacheco, las empresas eran muy reacias a gastar en cosas no directamente vinculadas con el trabajo extractivo ${ }^{64}$.

Pese a la previsión inicial, en 1928 el gobierno español se hizo cargo solamente del $50 \%$ de los gastos ocasionados por la campaña, porcentaje que aumentó ligeramente en 1929, de manera que el Inspector vio incrementado su sueldo en 2.000 ptas y se previó la contratación de un nuevo inspector de

63 «A general examination of the workmen carried out early in the year [1927] under official auspices showed only six cases of slight infection and these were promptly cured by treatment. As a result the mine has been officially declared free of the parasite, giving us the privilege, denied to all other mines under the regulations, of refusing admittance, if desired, to infected workmen from other mines». Report for the Year 1927 (1928). ARCHIVO HISTÓRICO PROVINCIAL DE JAÉN, Sección Minas del Centenillo, Libros copiadores de cartas, leg. 16463, p. 426. En dicho «reconocimiento general», llevado a cabo por González Comino a lo largo del mes de febrero de 1927, se practicaron 580 análisis de heces procedentes de otros tantos trabajadores de interior.

64 HERNÁNDEZ PACHECO, D. «A Report for 1927 of the campaign against ankilostomiasis in the mines of Spain», RAC, RF, 1.1, 795, 2, 14. Fue remitido a primeros de febrero, Strode a Russell, 15-02-1928, RAC, RF, 1.1, 795, 2, 13. 
salubridad minera, mientras que la Fundación aportó 10.360 ptas en 1928 y 10.000 en 192965 .

La marcha regular de los trabajos de inspección y, en particular, la actividad del laboratorio regional de la crítica zona de Linares, sufrió un sobresalto importante de la mano de la crisis de la minería del plomo. La mancomunidad de empresas, en el contexto de la baja de los precios del mineral, decidió recortar gastos y suspender el abono de los sueldos del personal encargado del laboratorio, en un momento en que el Inspector Pacheco se marchaba becado al extranjero (junio de 1929). Bailey solicitó de la IHB que se modificaran los términos del presupuesto anual aprobado, a fin de poder financiar la continuidad del director del laboratorio regional durante siete meses, y de un ayudante por seis meses ${ }^{66}$.

La campaña se mantuvo en los años siguientes, si bien no hemos encontrado más testimonios que los procedentes de la necesaria contribución de la IHB. Así, en 1930 se presupuestaron 26.100 ptas de coste del servicio, de las que el organismo norteamericano aportó $10.000^{67}$. Hemos de suponer que sus resultados fueron satisfactorios, aun cuando la colaboración de ninguno de los actores de la salud industrial fuera perfecta, incluso detectándose importantes resistencias. Esta es la conclusión del médico que dirigió una intervención en las minas de Puertollano en los veranos de 1931 y 1932, una zona en la que las actuaciones derivadas de la legislación profiláctica habían sido parcas por la resistencia encontrada a todos los niveles:

«Las empresas estimaban la lucha contra la anquilostomiasis como una intromisión abusiva en sus trabajos; en el mejor de los casos no prestaban interés ninguno, porque en su incomprensión sólo veían el perjuicio inmediato de la subida de coste de sus productos, o una molestia innecesaria. Los obreros, por su incultura, y los trastornos inherentes al tratamiento, hacíanse indisciplinados y rebeldes a los avisos. Y los médicos, empleados a sueldo de las Compañías y atacados de una especie de indolencia colectiva, dejaban pasar, cruzados de brazos, los acontecimientos, limitándose a cubrir el expediente en el sentido burocrático con cifras y datos, muchas veces de dudosa exactitud» ${ }^{68}$.

65 Strode a Russell, 23-08-1928, RAC, RF, 1.1, 795, 2, 13; Strode a Russell, 18-10-1928, RF, 1.1, 795, 2, 13.

66 Strode a Russell, 1-07-1929, remitiendo carta de Bailey a Strode, 25-06-1929, RAC, RF, 1.1, 795, 2, 13.

67 Strode a Russell, 2-08-1929, RAC, RF, 1.1, 795, 2, 13.

68 Martínez GonZÁLeZ, M. (1933), «La anquilostomiasis en las minas de Puertollano», Rev. San. Hig. Púb., 8 (1), 23-48. 
Con la llegada de la República se afrontó esta situación. En 1932, Puertollano albergaba 4.500 mineros repartidos entre nueve explotaciones, cinco de las cuales pertenecían a la Sociedad de Peñarroya. El médico de la lucha antipalúdica Manuel Martínez González llevó a cabo una intervención en la zona, desde mediados de julio de 1931 a finales de 1932, con alrededor de 1.300 análisis cada año, encontrando un porcentaje decreciente de sujetos positivos, 7 y $2,65 \%$, respectivamente. Las investigaciones familiares y de las huertas y corrales inmediatos no mostraron indicios de contaminación, salvo en mineros retirados, portadores de gusanos más que auténticos enfermos. Por su parte, los responsables locales de las Minas del Centenillo consideraron erradicada la enfermedad en 1935, al no haberse registrado caso alguno entre los trabajadores de interior en los tres años anteriores ${ }^{69}$.

Prueba indirecta del éxito de la intervención contra la anquilostomiasis de las minas es la fusión de la inspección sanitaria propia con la Comisión antipalúdica, a finales de 1930, de la que se convirtió en secretario Hernández Pacheco. Se retomaba, en cierta forma, el esquema de la vieja «Sanidad del Campo». Con esta fusión cobra relevancia la actividad profiláctica en otros espacios fuera del entorno minero, en particular determinadas zonas agrícolas.

\section{LA EXTENSIÓN CAMPESINA DE LA INFECCIÓN Y DE LA INTERVENCIÓN}

La existencia de casos de anquilostomiasis entre obreros agrícolas en zonas huertanas de Valencia y Murcia se había comenzado a difundir a raíz de las primeras intervenciones antipalúdicas oficiales (Emilio Luengo, con Aznar y Oquiñena, diagnosticó cinco casos en el poblado de El Mareny, comarca de Sueca, en el verano de 1923) y del viaje de la comisión Bailey, recogiendo noticias de facultativos locales, por ejemplo de la provincia de Murcia, Valencia y Castellón ${ }^{70}$. En Talavera de la Reina se detectó un caso, en un individuo venido de América, pero el gusano infectante era el europeo ${ }^{71}$.

69 Report for the Year 1935 (1936). ARCHIVO HISTÓRICO PROVINCIAL DE JAÉN, Sección Minas del Centenillo, Libros copiadores de cartas, leg. 16464, p. 492.

70 Guillamón, A. (1927), «El problema de la anquilostomiasis en la Huerta de Murcia. Memoria de la campaña de divulgación autorizada por el Excmo. Ayuntamiento y de los trabajos realizados», Separata de Estudios Médicos, Núm. 45, pp. 4-6 y 48-49 (conocemos que se publicó también en Medicina de los Países Cálidos, 1928); RodríGuez Fornos, F. (1926), «Contribución al estudio de la anquilostomiasis en el Reino de Valencia», Rev. Esp. Med. Cir., 9, 661-674; LUENGO (1927).

71 LUENGO, (1927), p. 613. 
Bailey solicitó realizar una investigación sistemática en las provincias donde era conocida la existencia de anquilostomiasis entre los obreros del campo $^{72}$. Finalmente, se acordó participar en un proyecto de lucha contra la anquilostomiasis en la Huerta de Murcia que organizaba el Ayuntamiento de la ciudad, por un periodo de cinco años, a partir de $1928^{73}$.

El argumento base de toda la intervención partía de constatar un «serio problema que afecta a la economía de la vega del Segura»; así pues, la enfermedad individual se transformaba en social por sus efectos sobre la productividad y riqueza agrícolas ${ }^{74}$. El Instituto Provincial de Higiene, por circular del 29 de julio de 1926, ordenó levantar un padrón sanitario, la construcción de retretes y prohibir el empleo de excrementos como abono. Más adelante, entre mayo y julio de 1927, el Ayuntamiento de la capital lanzó una campaña de divulgación en los centros escolares de la zona huertana (al estilo de lo que había realizado la Comisión Sanitaria de la Fundación Rockefeller en el Sur de los Estados Unidos). La campaña abarcó 29 escuelas y unos 4.000 asistentes. El equipo autor de la campaña estuvo formado por el inspector municipal de Sanidad de Murcia, Antonio Guillamón, los médicos Sardina y Abril y dos subalternos, Martínez y Esteve. Se impartía una conferencia explicativa, se daban consejos profilácticos y se tomaban muestras fecales para examen en el laboratorio municipal o en el del Instituto Provincial de Higiene, encontrándose parasitados un $13 \%$ de los escolares ${ }^{75}$. Las conferencias se acompañaban de la exposición de carteles murales de distinto contenido (sobre normas higiénicas, sobre evolución del parásito, sobre anomalías de la sangre). Se repartieron 7.000 juegos de cinco láminas que reproducían los carteles e incluían al dorso un resumen de lo explicado, así como un millar de cartillas y carteles para que sirvieran de objeto de estudio a los escolares durante el tiempo dedicado a la explicación de la higiene y la fisiología.

En 1928 comenzó el apoyo de la Fundación Rockefeller a través de la IHD, dentro del esquema económico que muestra la Tabla 1. El dinero se empleó en suplementar los sueldos de los médicos participantes, en construcción de letrinas y en los gastos de instalación y viaje ${ }^{76}$.

\footnotetext{
72 Bailey a Gunn, 4-01-1926, RAC, RF, 5, 1.2, 273, 3464.

73 Bailey a Russell, 29-09-1930, RAC, RF, 1.1, 795, 2, 15.

74 Guillamón (1927), p. 3.

75 Guillamón (1927), p. 10, pp. 14-16.

76 Revision of Budget No. 64368 -Spain- Hookworm Control - Murcia [a 25 de octubre de 1928], RAC, RF, 1.1, 795, 2, 15
} 
TABLA 1. Presupuesto de la campaña contra la anquilostomiasis en la huerta de murcia

\begin{tabular}{|l|c|c|}
\cline { 2 - 3 } \multicolumn{1}{c|}{} & Aportación municipal & Aportación IHD \\
\hline $1928^{1}$ & $10.000 \mathrm{pta}$ & $10.000 \mathrm{pta}$ \\
\hline $1929^{2}$ & $12.000 \mathrm{pta}$ & $10.000 \mathrm{pta}$ \\
\hline $1930^{3}$ & $14.500 \mathrm{pta}$ & $7.500 \mathrm{pta}$ \\
\hline $1931^{4}$ & $17.000 \mathrm{pta}$ & $5.000 \mathrm{pta}$ \\
\hline
\end{tabular}

Fuentes: (1) Strode a Russell, 23-08-1928, RAC, RF, 1.1, 795, 2, 15. (2) 28458 -Spain- Hookworm Control -Murcia- Appropiation and Budget (resolución IHD 28405) RAC, RF, 1.1, 795, 2, 15. (3) Strode a Russell, 2-08-1929, RAC, RF, 1.1, 795, 2, 15. (4) Bailey a Russell, 29-09-1930, RAC, RF, 1.1, 795, 2, 15

La campaña consistió en una mezcla de información, diagnóstico masivo y educación sanitaria sobre el manejo de heces, con la instalación de retretes para coartar la infección superficial de los suelos agrícolas y urbanos. La dirección de la campaña se encomendó a Hernández Pacheco, y se desarrolló a satisfacción de los norteamericanos ${ }^{77}$. Como en el caso de la sanidad minera, esta intervención preparaba otra de mayor alcance, pues desde el principio se pensó que este servicio sirviera de ancla para la creación de un centro de salud comarcal $^{78}$. Por propia iniciativa y financiación españolas, se había incrementado la tarea de los dispensarios de anquilostomiasis con trabajo antipalúdico y vacunación $B C G$, a través de la lucha oficial antipalúdica ${ }^{79}$. Ésta había comenzado en julio de 1927 y en 1928 corría a cargo de Fernando Oquiñena, de probada familiaridad con el seguimiento de la anquilostomiasis. La sinergia entre ambos objetivos antiparasitarios permitió la creación de una oficina sanitaria polivalente, a partir de 1929, que abarcaba el estudio de las enfermedades transmisibles (con especial atención al tracoma, anquilostomiasis y paludismo), la inspección médica de la infancia, la educación sanitaria y el pequeño saneamiento, incluyendo la construcción de retretes con cargo al presupuesto sanitario $^{80}$. A finales de 1930 se produjo la fusión organizativa de la lucha antipalú-

77 G.K. Strode's Diary. Spain, May 1-10, 1930 (continued), RAC, RF, 1.1, 795, 2, 15.

78 Strode a Russell, 30-10-1928, RAC, RF, 1.1, 795, 2, 15; o una organización sanitaria más permanente, como en Strode a Russell, 2-08-1929, RAC RF, 1.1, 795, 2, 15.

79 Strode a Russell, 6-06-1930, RAC, RF, 1.1, 795, 2, 15. RodríGUEz OCAÑA, BALlESTER AÑón, Perdiguero, MEdina DomÉneCh, Molero, (2003), pp. 152-153.

80 Hernández-PaCheCo, D.; ABril CÁnOvas, M. (1932), «Ensayo de higiene rural en la huerta de Murcia. Resumen de los trabajos realizados durante el primer semestre de 1931» 
dica y la sanidad minera, lo que reforzó esta colaboración tanto en las zonas mineras de la provincia de Jaén como en la Huerta de Murcia.

En mayo de 1931 se produjo la retirada del apoyo municipal murciano, lo que supuso la finalización abrupta del proyecto y, pese a los intentos del nuevo Inspector provincial de Sanidad, Laureano Albadalejo, el fin de la implicación de la IHD en la sanidad murciana. Ya un año antes, un visitante norteamericano había abandonado la antigua opinión optimista sobre el futuro de la colaboración con Murcia, debido, entre otras razones, a que la puesta en práctica de un servicio de personal médico con dedicación exclusiva era «the principle most difficult to establish in Spain $\rangle^{81}$. Esto no impidió la continuación de las actuaciones sanitarias, si bien bajo la exclusiva dependencia de la Dirección General de Sanidad e Instituto Provincial de Higiene. Apoyado en la organización allí formada, el laboratorio de Parasitología de la Facultad de Medicina de Madrid desarrolló el estudio más extenso sobre la relación entre el crecimiento y las parasitosis de la población infantil en la comarca huertana, de todo el tiempo de la República ${ }^{82}$.

¿Por qué no hubo preocupación por la anquilostomiasis en las zonas agrícolas hasta fechas tan tardías? El reducido número de enfermos graves que se encontraba en la Huerta murciana, mientras que era elevado el de portadores (personas infectadas con menos de 25 gusanos), indicaba que los terrenos presentaban una baja densidad de gusanos; lo cual permite suponer que soportaban el suministro de huevos de anquilosotoma desde hacía relativamente poco tiempo. Antonio Guillamón encontró que la crisis minera de la zona de la Unión, a partir de 1915, podía dar razón tanto de la cronología como de la procedencia primitiva de los parásitos, tanto por el flujo migratorio generado desde aquellas zonas mineras, como por el empleo agrícola como abono de heces humanas procedentes de los campamentos mineros, transportadas en los mismos carros donde se acarreaban las hortalizas frescas a tales lugares ${ }^{83}$. Otro aspecto a tener en cuenta era el de la escasa familiaridad de los médicos rurales con esta parasitosis, que podría haberse visto enmascarada por otros diagnósticos, si bien el recurso al hemograma se había extendido desde los años de la década de 1910, según el testimonio antes citado de Guillamón.

y «Estudio sanitario de un partido rural en la huerta de Murcia», Rev. San. Hig. Púb., 7, 219223; 839-848.

81 G.K. Strode's Diary. Spain, May 1-10, 1930 (continued), RAC, RF, 1.1, 795, 2, 15.

82 Darriba, A. R.; Abril CÁnovas, M. (1933-34), Sobre la anquilostomiasis en la huerta de Murcia, Madrid, Publicaciones Oficiales de la C.P.I.S., 2 vols.

83 GuILlamón (1927), pp.8-9. 
En conclusión, podemos observar que la fundamentación prestada por el laboratorio (en este caso, parasitológico) justificó una campaña sanitaria y la dotó de una ambición erradicadora, a la vez que estimuló el ejercicio de la educación sanitaria. A primeros del siglo, hemos visto que el hallazgo azaroso, si bien continuo, de casos de anquilostomiasis se acompañó de una retórica de hecatombe de corte productivista. Su visibilización como enfermedad social se produjo gracias a su percepción como un problema de salud pública controlable a través de la identificación de los enfermos y los portadores mediante pruebas de laboratorio, la disponibilidad de un tratamiento eficaz y la posibilidad de intervención con medidas de higiene general y ambiental. Tras el reglamento de policía minera de 1897 y la ley de accidentes de 1900, la legislación sobre anquilostomiasis en las minas de 1912 y 1926 fue la única intervención estatal encaminada a la protección de la salud de los trabajadores. Como la primera de las citadas, se dirigía tanto a las empresas como a los obreros, si bien las obligaciones de estos últimos resultaron más fácilmente exigidas (a través de la pérdida del trabajo, en los supuestos de contratados portadores de gusanos en minas exentas, o de la retención de parte del salario para tratamiento). La puesta en práctica de la legislación contra la anquilostomiasis tuvo un seguimiento muy desigual por parte de las compañías mineras, ligado al tamaño de las explotaciones y a la disponibilidad de mano de obra. En el caso de las Minas del Centenillo en la comarca de Linares-La Carolina, una de las zonas con mayores niveles de afectación, la combinación de la intervención ambiental, las técnicas de laboratorio y las medidas coercitivas sobre los trabajadores mostró su efectividad. El estudio de la distribución del anquilostoma duodenal desempeñó un lugar central en la estrategia de la IHB/IHD de la Fundación Rockefeller en España. El apoyo de esta organización resultó decisivo para consentir el desarrollo del andamiaje legislativo y profesional con que se hizo frente a este problema parasitario. Y su concreción en el medio rural coadyuvó a extender el modelo de centros de higiene que adoptaría posteriormente la República.

Fecha de recepción: 14 de abril de 2005

Fehca de aceptación: 20 de febrero de 2006 